Yule's 'Characteristic' and the 'Index of Diversity'

THERE have recently been two attempts to study the problem of random sampling from a mixed population in which all the constituent groups are not equally abundant.

R. A. Fisher ${ }^{2}$ studied the problem of random samples of a population of insects in which the species were not equally abundant. Making the assumption that the frequency distribution in the population sampled might be of Eulerian form, he showed that the frequency in the sample should then be a negative binomial, or in certain simplified cases a logarithmic series $n_{1} ; \frac{n_{1} x}{2} ; \frac{n_{1} x^{2}}{3}$, etc., where $n_{1}$ is the number of groups with one unit and $x$ is a constant (for the sample) less than unity.

He was also able to show that in this case the ratio of $\frac{n_{1}}{x}$ is constant for all samples from the same population and therefore it is a property of the population. We have called this the 'Index of Diversity' $(\alpha)$ and the theory has been found to fit in well and to be a useful

weapon in many biological problems ${ }^{2,8}$. Udny Yule $^{4}$ has attacked a somewhat similar problem in a study of the frequency distribution of different nouns in random samples of nouns taken from writing by various authors. Making the genera assumption that the frequency of different nouns in the population (which is the 'mind' of the author) is such that it has a mean $M$ and a standard deviation $\sigma$, he shows that in all samples from the same population $\frac{S_{2}-S_{1}}{S_{1}{ }^{2}}$ should be a constant, when $S_{1}$ and $S_{2}$ are the first and second moments of the observed frequency series in the sample (that is, $\Sigma f_{x x}$ and $\Sigma f_{x} x^{2}$ ). This is shown to be more or less correct in several samples taken from the same work.

I think it is therefore of interest to point out that in the logarithmic series suggested by Fisher.

and hence it follows that

$$
S_{1}=\frac{n_{1}}{1-x} \text { and } S_{2}=\frac{n_{1}}{(1-x)^{2}},
$$

$$
\frac{S_{2}-S_{1}}{S_{1}^{2}}=\frac{x}{(1-x) S_{1}}=\frac{x}{n_{1}}=\frac{1}{\alpha} \text {. }
$$

In other words, when the logarithmic series is applicable, Yule's Characteristic $\left(1,000 \times \frac{S_{2}-S_{1}}{S_{1}{ }^{2}}\right)$ is proportional to the reciprocal of our "Index of Diversity".

I have worked out the ' $\alpha$ ' values for certain of Yule's samples of nouns, and Yule's 'characteristic' $(K)$ for several of my light-trap samples of insects as follows:

\begin{tabular}{cccc} 
& \multicolumn{4}{c}{ NoUNS IN MACAULAY's EsSAY oN BACON } \\
Sample & No. of units & No. of groups & $\alpha$ \\
1 & 2000 & 903 & 61 \\
2 & 2041 & 964 & 67 \\
3 & 4004 & 1409 & 78 \\
4 & 4049 & 1432 & 79 \\
5 & 8045 & 2048 & 88
\end{tabular}

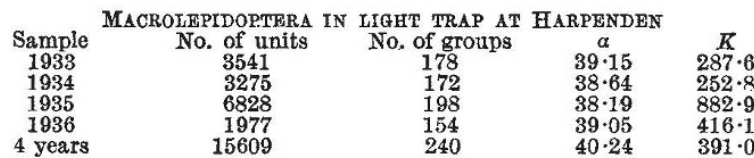

From this it will be seen that in the noun samples (which are not in logarithmic series) $\alpha$ is variable, but $K$ very constant; but in the moth samples the reverse is the case.

Further investigation is much needed both on the mathematical side and in testing against biological data.

Rothamsted Experimental Station,

C. B. WILLIAMS.

$$
\begin{aligned}
& \text { Harpenden. } \\
& \text { Jan. } 8 .
\end{aligned}
$$

Fisher, Corbet and Williams, J. Animal Ecol., 12, 42 (1943).

Williams, J. Ecol., 32, 1 (1944).

${ }^{3}$ Williams, Ann. Eugenics, 12,143 (1944).

"Yule, "Statistical Study of Literary Vocabulary" (Cambridge, 1944).

\section{Micro-stimulation of the Human Retina}

BY correcting the chromatic difference of magnification of the lenssystem of the eye, and by using very small test objects as stimuli, it has been found possible to construct a plan showing the approximate positions of some of the photo-receptors of my own aft retina. Four methods have been employed and their results correlated.

(1) Retinal astigmatism using a special test object. This showed that the maximum acuity area for green light was $T$-shaped, $L$-shaped or +-shaped.

(2) The relative positions of the flxation points for red, green and blue liuht. They were found to form an acute-angled triangle with blue light. They were found to form an acute-angled triangle with

(3) The apparent colour of a tiny neutral grey disk, placed in various positions around the green fixation point.

(4) The size of the area of most acute vision.

of the three possible shapes for the maximum acuity area for green light, the $T$-shape was found to flt in best with the other data; see Nos. $4,5,6$ and 8 on plan.
PROVISIONAI PLAN FOR THE PHOTO-RECEPTORS OF THE HUMAN FOVEA.

$\begin{array}{ccc}\text { No. } 1 & \text { No. } 2 & \text { Red } \\ \begin{array}{cc}\text { Red } \\ \text { No. } 4\end{array} & \text { No. } 5 & \text { No. } 6 \\ \text { Green } & \text { Green fixation } & \text { Green } \\ \text { No. } 7 & \text { No. } 8 & \text { No. } 9 \\ \text { Red fixation } & \text { Green } & \text { Blue fixation }\end{array}$

Each area contains from four to nine cones. The middle green area No. 5 is the flxation point for green; No. 7 is that for red, and No. 9 that for blue. Areas 4, 5, 6 and 8 are normally used for seeing fine detail by white light, for example, when reading smaIl print. Since the retinal image is inverted by the lens system of the eye, the up strokes of the letters fall on area 8 .

The collection of sense organs of any one kind into areas as shown on the plan is in accordance with the cluster hypothesis. Cluster formation of a similar kind is seen in the Lumiere screen used for colour photography. This screen is prepared by mixing starch grains, some red, some green and some blue, together. The clusters of grains are easily seen with a low-power magnifer. They cause the screen to have a mottled appearance.

Physiological Department,

H. HARTRIDGE.

St. Bartholomew's Hospital Medical College, c/o Zoological Department, University of Cambridge. Jan. 14.

\section{Food and the Digestive Processes of the Lamellibranchs}

IN most of the recent literature ${ }^{1,2}$ concerning the food; feeding habits and digestive processes of the lamellibranchs, it is claimed: (1) that the food of this class (septibranchs excepted) consists of minute particles mainly of plant origin; (2) that the digestion of protein and fat is exclusively intracellular and takes place either in the cells of the digestive diverticula or in wandering phagocytes; (3) that the digestive diverticula are not organs of secretion.

3) that the digestive diverticula are not organs of secretion.
The results of studies carried out in the Department of Zoology,

The results of studies carried out in the Department of Zoology,
Fouad I University, Cairo, and the Marine Biological Station, Fouad I University, Cairo, and the Marine Biological Station, Ghardaqa, on Tridacna elongata, T. squamosa, Pinctada vulgaris, Ostrea cucullata, other Ostrea species, two species of Mytidur
prosidens are contrary to the above-mentioned claims.

prosidens are contrary to the above-mentioned claims. Examination of the stomach contents of the marine forms soon
after being caught or soon after being fed invariably showed the after being caught or soon after being fed invariably showed the presence of ordinary net zooplankton, for example, copepods of about $1.5 \mathrm{~mm}$. in length, larvæ of Crustacea, etc., either whole or undergoing digestion. Tridacna, which is claimed by Yonge to subsist mainly on the zooxanthellæ it harbours and to be incapable of tak

in food particles $14 \mu$ in diameter was found to be no exception ${ }^{4}$. and Pinctada proved the presence of free proteolytic and lipolytic enzymes as well as of those acting on carbohydrates

The claim that the digestive diverticula are not secreting organs has been supported by the negative results of the iron-injection technique ${ }^{8}$. However, previously starved specimens of Unio, of which both digestive diverticula and fæces had become free of any colouring matter and which were kept on colourless food and injected in the foot with a chlorophyll solution, showed subsequently brown-greenish globules in the cells of the diverticula. These globules were later observed in the lumen of the gut. By and by the fæces became browngreenish in colour. The passage of the colouring matter from the blood into the lumen of the gut through the cells of the diverticula is an indication of the secreting action of these organs.

K. MANSOUR.

Department of Zoology,

Fouad I University,

$$
\text { Feb. } 28 .
$$

1 Yonge, C. M., Biol Rev., 12, 87 (1937)

2 Coe, W. R., and Fox, D. I., Biol. Bull., 87. 59 (1944).

Yonge, C. M., Great Barrier Reef Expedition Scl. Rep., 1, No. 11 (1936).

- Mansour, K., Proc. Egyptian Acad. Sci., 1 (1946) (in the press).

5 Mansour-Bek, J. J., Proc. Egyptian Acad. Sci., 1 (1946) (in the press). - Yonge, C. M., Trans. Roy. Soc. Edin., 54, 703 (1936).

\section{Tissue Changes in Experimental Mice Treated with Pentose Nucleotides}

TIssue changes in mice injected with a commercial mixture of the four pentose nucleotides of ribonucleic acid have been previously described ${ }^{1}$. Observations on normal and tumour-bearing mice treated with guanylic, adenylic, cytidylic and uridylic acids have now shown with guanylic, adenylic, cytidylic and uridyle acids have now shown changes in.the tissues

dividual nucleotides. Tumour-bearing mice. The accompanying table shows the resuits
of administering nucleotides, and also sodium phosphate used as a of administering nucleotides, and also sodium phosphate used as a solvent, by injection into pure-line $(\mathrm{C57}, \mathrm{CBA})$ mice grafted with homologous methylcholanthrene sarcomas. It suggests that the purin nucleotides, adenylic and guanylic acids, exert inhibitory actions on tumour-growth, whereas the pyrimidine nucleotide, cytidylic acid has little or no effect, and that uridylic acid exercises a promoting ation on tumour development.

Examination of splenic changes accompanying the growth of the sarcomas showed that the spleens of mice in Groups 1 and 4 were decreased in weight as compared with the controls, and the number of giant cells per unit area markedly lessened. Mice of Groups 3 and
5 showed increase of splenic weight compared with the controls, 